\title{
Saúde e Prevenção nas Escolas (SPE): \\ elementos para avaliação de projetos sociais em Juazeiro, Bahia, Brasil
}

Marcelo Silva de Souza Ribeiro(a)

Carla Valois Ribeiro ${ }^{(b)}$

Ribeiro MSS, Ribeiro CV. Health and prevention at schools: elements for evaluating social projects in Juazeiro, Bahia, Brazil. Interface (Botucatu). 2015; 19(53):337-48.

\begin{abstract}
"Health and prevention at schools" was a course completion project presented by this author at the time of being a student in the multidisciplinary family health residency program. It was a health education initiative that promoted a sexual and reproductive health activity for adolescents in the municipality of Juazeiro, Bahia, Brazil. The present study aimed to analyze the conception, methodology and results of this project, taking into consideration its intersectoral action, health-education interface and social effectiveness. Timely completion of this work ensured sustainability for the project and encouraged participation by the school community. The ramifications of the project are shown in the healthcare and education macropolicies that today direct the major intersectoral pacts within this scenario. Thus, an understanding of its construction is required so that it can be strengthened.
\end{abstract}

Keywords: Health. Education. Intersectoral action. Social effectiveness.
O SPE, à época, apresentado como trabalho de conclusão de curso (TCC) de Residência Multiprofissional em Saúde da Família, pela autora, então discente do programa, representou uma iniciativa de saúde e educação, promovendo uma atividade de saúde sexual e reprodutiva para adolescentes no Município de Juazeiro/ BA, Brasil. O objetivo deste trabalho foi analisar o SPE em sua concepção, metodologia e resultados, considerando a intersetorialidade, a interface saúde e educação e a efetividade social. Concluiuse que foi oportuna a garantia da sustentabilidade do projeto e o fomento à participação da comunidade escolar. Os desdobramentos do SPE são visualizados nas macropolíticas de atenção à saúde e educação que hoje direcionam as principais pactuações intersetoriais deste cenário, demandando a compreensão de sua edificação para seu fortalecimento.

Palavras-chave: Saúde. Educação. Intersetorialidade. Efetividade social. (a) Universidade Federal do Vale do São Francisco. Av. José de Sá Maniçoba, s/n, Centro. Petrolina, PE, Brasil.marcelo.ribeiro@ univasf.edu.br (b) Secretaria de Saúde de Pernambuco. Petrolina, PE, Brasil. carla_valois@ hotmail.com 


\section{Introdução}

Este estudo está inserido no âmbito da avaliação das políticas públicas diretamente relacionadas à saúde materno-infantil, por meio da qual é possível compreender as necessidades humanas com vistas à tomada de decisões neste contexto. Particularmente, a interface saúde-educação tem impactado, nas politicas públicas e nas ações, temas como: sexualidade, desenvolvimento infantil, relações familiares, condição de gênero, dentre outros considerados significativos para a superação dos desafios sociais. Este trabalho partiu, portanto, do entendimento de que as políticas públicas em saúde devem estar articuladas com a educação, elegendo estratégias de construção coletiva e solidária, sobretudo para garantir a intersetorialidade das ações e, consequentemente, sua efetividade social. A seguir, alguns pontos sobre essa articulação e seus respectivos desdobramentos serão depreendidos.

Do ponto de vista das recentes conquistas políticas, a Saúde e a Educação foram considerados direitos fundamentais e garantidos segundo a Constituição Federal ${ }^{1}$, para a qual essas conquistas também concebem uma relação indissociável em Saúde e Educação incluindo, também, os pressupostos de cidadania e empoderamento. Um outro ponto a ser destacado é o conceito de Território segundo Faria e Bartolozzi ${ }^{2}$, que torna possível reconhecer a dinâmica e os dispositivos sociais que, de modo integrado, subsidiam o enfrentamento das principais vulnerabilidades.

Acredita-se que, na essência da educação, encontram-se os valores de formação humana e social, sendo a saúde entendida como essencial condição de dignidade humana que requer, para além de limites orgânicos, dimensões sociopolíticas, territoriais, de convivência e singularidades.

A relação Saúde e Educação para Freire 3 , portanto, com base no território, dialoga com o mesmo, problematiza e elabora um saber relacional, como síntese entre os saberes apreendidos na escola da vida e os proclamados na vida da escola.

A compreensão da relação entre Saúde e Educação, ao constituir-se de direitos de cidadania, propõe a elaboração de políticas públicas que deem concretude aos compromissos em pauta, justificadas pela integralidade, e que não podem ser concebidas de forma fragmentada.

O processo de integração entre os setores, portanto, caracteriza-se como um processo de educação permanente. Considerando a educação como emancipação que propicia o diálogo e aprendizagens mútuas que facilitam a compreensão da saúde em sentido ampliado, sitiados em um território definido, segundo o qual Fonseca ${ }^{4}$ concebe a intersetorialidade, possível a partir da convergência solidária e corresponsável.

Uma ação governamental que busca apreender todo esse processo de integração é o Projeto Saúde e Prevenção nas Escolas (SPE). Tal projeto, lançado pelo Ministério da Saúde ${ }^{5}$, é uma iniciativa interministerial, criada em 2003 pelos Ministérios da Saúde e da Educação, cujo objetivo é a promoção da saúde sexual e reprodutiva com vistas à redução das vulnerabilidades de adolescentes e jovens: às doenças sexualmente transmissíveis (DST/HIV/Aids), à gravidez não planejada, ao uso de psicoativos. Além disso, visa fomentar o protagonismo juvenil na participação da elaboração de políticas públicas.

A partir do que foi colocado, este trabalho apresentou uma análise do Projeto Saúde e Prevenção nas Escolas (SPE), implementado no município de Juazeiro - Bahia, nos anos de 2009, 2010 e 2011, na perspectiva da interface Saúde e Educação.

A afinidade da pesquisadora, profissional de saúde, com o tema foi motivada pela participação da mesma nos processos disparados pelo SPE junto a profissionais de saúde e educação. Na oportunidade, a vivência em discussões relacionadas aos setores saúde e educação suscitou interesse em pesquisar sobre o assunto. Estudar esta relação é importante quando se vislumbra a potencial ferramenta de intersetorialidade, essencial para a elaboração de práticas integrais e integradas. A escassez de estudos que analisem políticas públicas e projetos sociais torna iminente o uso deste tipo de ferramenta de avaliação, tendo em vista o impacto político e social que estes produzem em seus contextos.

Quanto ao objetivo geral, pretendeu-se analisar o Projeto Saúde e Prevenção nas Escolas em Juazeiro - Bahia, em sua concepção, metodologia e resultados, disponíveis em documentos oficiais e institucionais. Dentre os objetivos específicos, buscou-se analisar o Projeto Saúde e Prevenção nas Escolas considerando os seguintes conteúdos: a intersetorialidade, a interface Saúde e Educação e a efetividade social. 
Este estudo apoiou-se em alguns pressupostos. O primeiro é a ideia de que inserir o SPE nas agendas políticas potencializa práticas já existentes e possibilita a elaboração de novas ofertas, integrais e integradas. O segundo seria o de que o SPE aproxima sujeitos e subjetividades dos atores que o protagonizam. Finalmente, o terceiro tem a ver com a ideia de relacionar Saúde e Educação utilizando o dispositivo SPE promovendo ações intersetoriais socialmente efetivas.

\section{Métodos}

O presente estudo constituiu uma pesquisa de base documental de fontes impressas, na qual, segundo a obra de Laville ${ }^{6}$, os documentos utilizados incluíram publicações de organismos, correspondências, dossiês e publicações científicas relacionadas ao Projeto Saúde e Prevenção nas Escolas. A análise também contemplou a vivência da pesquisadora nos processos disparados pelo projeto.

Os dados foram acessados a partir de consultas a arquivos públicos situados nas Secretarias Municipais de Saúde e Educação de Juazeiro - BA. O acesso aos mesmos foi facilitado por ser a pesquisadora então membro do Grupo Gestor Municipal do SPE. Estes documentos foram relevantes construções intersetoriais e por tal razão foram selecionados. Optou-se por incluir produções oficiais e institucionais, nacionais, consonantes aos objetivos da pesquisa, coerentes com a temática SPE, excluindo-se todos os demais que não convergiam com a mesma. A conveniência do acesso e a pertinência da escolha foram valiosos critérios de inclusão.

Os conteúdos basilares ao desenvolvimento deste estudo utilizaram como referência: 1) Guia para a formação de profissionais de saúde e educação do SPE, de elaboração do Ministério da Saúde em 2008, que apresenta uma proposta estrutural e metodológica para implementação do Projeto ${ }^{5}$; 2) Manual Diretrizes para implementação do projeto SPE, constructo que direciona a proposta políticoideológica do Projeto, publicação do Ministério da Saúde do ano 20087; 3) Caderno de Atenção Básica Saúde na Escola, elaborado pelo Ministério da Saúde em 2009, enuncia o Programa Saúde na Escola e demonstra estratégias de articulação intersetorial para a promoção da saúde escolar ${ }^{8}$; 4) Projeto municipal do SPE, de construção do GGM de Juazeiro em 2009, apresenta a versão preliminar do processo de trabalho a ser implementado9; 5) Decreto Municipal número 489/2009, da Prefeitura Municipal de Juazeiro - Bahia, institui o Grupo Gestor Municipal para a implantação e implementação do SPE, demonstrando suas funcionalidades e nomeando representações intersetoriais para a composição do referido grupo ${ }^{10}$; 6) O informativo Relação das Escolas - SPE - 2009, 2010 e 2011, de construção do GGM em 2011'11, e 7) o instrumento de monitoramento, elaborado pelo GGM em 2011 e apresentado ao Grupo Temático Selo UNICEF ${ }^{12}$.

Segundo $\mathrm{Gil}^{13}$, a pesquisa documental utiliza materiais que ainda não receberam tratamento analítico ou ainda podem ser reelaborados. Os documentos considerados de primeira mão, neste estudo, configuraram-se a partir das publicações oficiais, o projeto municipal de Juazeiro e o decreto municipal que discorre sobre o SPE. Os documentos de segunda mão, obedecendo aos critérios do autor, constituíram relatórios de pesquisa e avaliação interinstitucionais, de elaboração do Grupo Gestor do SPE de Juazeiro.

A análise destes documentos foi imperativa à confecção de aproximações e distanciamentos entre as fontes, assegurando o alcance dos objetivos desta pesquisa.

O tratamento dos dados seguiu a técnica da análise de conteúdo, sobre a qual Gil ${ }^{13}$ considerou possibilitar a elucidação do conteúdo expresso e latente das comunicações. A análise de conteúdo é desenvolvida em quatro fases: a) pré-análise, com a escolha de documentos; b) elaboração de hipóteses e preparo de materiais; c) exploração do material que consiste na escolha das unidades, enumeração e classificação; d) e o tratamento, inferência e interpretação dos dados. 


\section{Resultados}

Os documentos acessados, por suas características elementares, foram aproximados e agrupados da seguinte forma:

1. Publicações e documentos oficiais: produções interministeriais que discorreram sobre projetos e programas intersetoriais na perspectiva da interface saúde e educação - Guia para a formação de profissionais de saúde e educação do SPE ; Manual Diretrizes para a implementação do projeto SPE'; Caderno de Atenção Básica Saúde na Escolå ${ }^{8}$.

2. Construtos elaborados pelos atores sociais locais: publicações locais pautadas nas vivências e demandas locais - Projeto municipal do SPE9; Decreto Municipal 489/200910.

3. Relatórios de avaliação: documentos situacionais para o monitoramento de implementação do projeto - Informativo Relação das Escolas - SPE - 2009, 2010 e 201111; Instrumento de Monitoramento ${ }^{12}$.

\section{Concepção}

1.1 Quanto às concepções do primeiro grupo de documentos, o Guia ${ }^{5}$ orientou a construção de um saber compartilhado, concebendo o SPE como um marco de integração saúde-educação, pressupondo a articulação de políticas com vistas à produção de transformações efetivas nas condições de vulnerabilidade; enquanto o Manual Diretrizes ${ }^{7}$ contemplou o processo planejado e participativo das ações e consolidação das políticas públicas norteadas a partir de elementos de intersetorialidade, apresentando o projeto como um convite a esta integração e demais organizações da sociedade civil, privilegiando o espaço da escola como cenário de reorientação e inclusão de práticas e construção de espaços de diálogo como resposta social às vulnerabilidades. O Caderno de Atenção Básica ${ }^{8}$, por sua vez, apresentou conceitos de: cooperação e respeito às singularidades, estímulo à intersetorialidade, compromisso com a integralidade, fortalecimento da participação social.

1.2 Dentre os construtos do segundo grupo, quanto às concepções, o Projeto municipal ${ }^{9}$ destacou o SPE como marco de integração saúde-educação, privilegiando a escola como espaço de participação dos sujeitos: estudantes, famílias, profissionais da educação e da saúde. O Decreto ${ }^{10}$, em consonância com o primeiro, instituiu o Grupo Gestor Municipal do SPE considerando seu caráter intersetorial para a formulação de políticas públicas articuladas, prevendo as atribuições do GGM à luz da efetividade social, enfatizando a educação inclusiva e a participação da comunidade escolar para a construção do papel democrático da escola.

1.3 Dentre os relatórios de avaliação, o Informativo ${ }^{11}$ tabulou a relação nominal das escolas que participaram da formação SPE nos períodos 2009, 2010.1, 2010.2 e 2011.1, dispondo: a quantidade de alunos por unidade escolar, a implantação do SPE na unidade, a visita de monitoramento e a quantidade de professores formados. Sitiou a implantação do SPE no setor educação, sendo as informações, portanto, limitadas a este setor. A condicionalidade da efetividade social do projeto foi demonstrada timidamente pela formação de professores e consequente implantação ou não do SPE na unidade escolar. O documento foi de produção do GGM. O Instrumento de Monitoramento ${ }^{12}$ também relacionou escolas e implantação do projeto SPE. Foi elaborado por membros do GGM, mas configurase como um olhar sobre o território da escola. O Quadro 1 sintetiza a Concepção do SPE quanto aos elementos de intersetorialidade, interface saúde-educação e efetividade social. 
Quadro 1. Concepções do SPE sob a luz da intersetorialidade, interface saúde-educação e efetividade social.

\begin{tabular}{|l|l|l|l|}
\hline \multirow{2}{*}{ Documentos } & \multicolumn{3}{|c|}{ Concepções } \\
\cline { 2 - 4 } & \multicolumn{1}{|c|}{ Intersetorialidade } & \multicolumn{1}{|c|}{ Interface Saúde-Educação } & Efetividade social \\
\hline $\begin{array}{l}\text { Publicaçães e } \\
\text { documentos } \\
\text { oficiais }\end{array}$ & $\begin{array}{l}\text { SPE como processo planejado } \\
\text { e participativo das políticas } \\
\text { públicas - elementos de } \\
\text { intersetorialidade (MD) } \\
\text { Estímulo à intersetorialidade, } \\
\text { escola como espaço de } \\
\text { relaçães (CAB) }\end{array}$ & $\begin{array}{l}\text { SPE como marco de integração } \\
\text { saúde-educação (GF) } \\
\text { Território como espaço de produção } \\
\text { de vida e da saúde, ESF no processo } \\
\text { de cuidado (CAB) }\end{array}$ & $\begin{array}{l}\text { Articulação de políticas com vistas } \\
\text { às transformações efetivas nas } \\
\text { condições de vulnerabilidades (GF) } \\
\text { A escola como cenário de } \\
\text { reorientação e inclusão de práticas } \\
\text { e construção de diálogo como } \\
\text { resposta social (MD) }\end{array}$ \\
\hline $\begin{array}{l}\text { Construtos } \\
\text { elaborados } \\
\text { pelos atores } \\
\text { sociais }\end{array}$ & $\begin{array}{l}\text { Caráter intersetorial do GGM } \\
\text { (Dec) }\end{array}$ & $\begin{array}{l}\text { Escola como espaço de participação } \\
\text { dos sujeitos (PrM) } \\
\text { GGM para a formulação de políticas } \\
\text { articuladas e integradas (Dec) }\end{array}$ & $\begin{array}{l}\text { Efetividade social a partir do } \\
\text { GGM pela construção do papel } \\
\text { democrático da escola (Dec) }\end{array}$ \\
\hline $\begin{array}{l}\text { Relatórios de } \\
\text { avaliação }\end{array}$ & Olhar sobre o Setor Educação & $\begin{array}{l}\text { Relação nominal por ano das escolas } \\
\text { e suas peculiaridades (IR) } \\
\text { Relação nominal de escolas } \\
\text { relacionadas à implantação do SPE } \\
\text { (IM) }\end{array}$ & $\begin{array}{l}\text { Pela formação de professores e } \\
\text { implantação do SPE (IR) }\end{array}$ \\
\hline
\end{tabular}

$\mathrm{GF}=$ Guia para a formação de profissionais de saúde e educação do SPE; MD= Manual Diretrizes para implementação do projeto SPE; $C A B=$ Caderno de Atenção Básica Saúde na Escola; PrM= Projeto municipal do SPE; Dec= Decreto Municipal 489/2009; IR= Informativo Relação das Escolas - SPE - 2009, 2010 e 2011; IM= Instrumento de Monitoramento

\section{Metodologia}

2.1 Quanto à metodologia do primeiro grupo, o Guia ${ }^{5}$ direcionou uma sequência de oficinas que requer planejamento conjunto e de formação intersetorial para profissionais de saúde e educação, propondo a inclusão de outros dispositivos sociais, utilizando de metodologia participativa pautada na emancipação. O Manual Diretrizes ${ }^{7}$ apoiou a concretização do projeto na formação continuada de profissionais de saúde e educação, enunciou a formação de grupos de trabalho e elaboração de Plano de Ação, com suas condições de efetividade. Articulou o impacto das iniciativas na elaboração dos projetos político-pedagógicos das escolas e da programação das ações em saúde do município. O Caderno de Atenção Básica ${ }^{8}$ apresentou conteúdos de intersetorialidade e interface saúde-educação pelas ofertas de: avaliações clínicas, nutricionais, oftalmológicas, de saúde e higiene bucal, auditiva e psicossocial, promoção da alimentação saudável, da saúde sexual e reprodutiva, da cultura de prevenção, redução da morbimortalidade por acidentes e violências, atualização do calendário vacinal, prevenção e redução do consumo de álcool e do uso de drogas, controle do tabagismo, educação permanente em saúde, atividade física e inclusão das temáticas de educação em saúde no projeto político-pedagógico das escolas.

2.2 No segundo grupo de documentos, quanto à metodologia, o Projeto municipal ${ }^{9}$ demonstrou o processo de trabalho estruturado a partir de oficinas temáticas com professores e profissionais de saúde, estabelecendo a formação de periodicidade quinzenal, com as temáticas seguintes: sexualidade, família, saúde e escola; relações de gênero; anatomia e fisiologia do sistema reprodutor masculino e feminino/gravidez na adolescência; escola e comunidade juntas na prevenção das DSTs; métodos contraceptivos e avaliação. O Decreto ${ }^{10}$ estruturou a composição do Grupo Gestor Municipal do SPE e normatizou o seu funcionamento. 
2.3 No terceiro grupo de documentos, o Informativo ${ }^{11}$ relacionou o quantitativo de 66 escolas municipais (Gráfico 1) e a evolução histórica do projeto. Em dez escolas, a formação ocorreu em 2009. Em 2010.1 a mesma foi promovida em 11 unidades. Em vinte unidades, a formação ocorreu em 2010.2. Em 2011.1, 25 escolas foram contempladas com a formação SPE. Dez escolas foram convidadas e não participaram da formação do SPE (Gráfico 1).

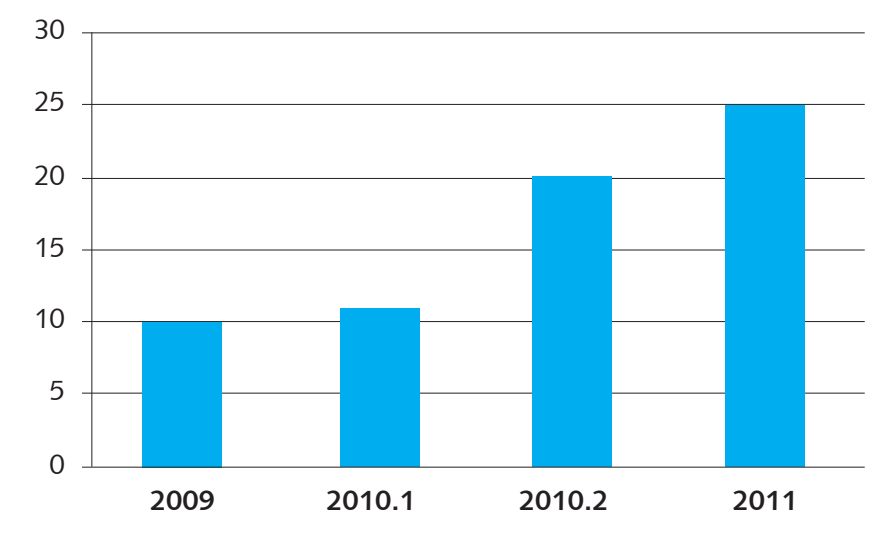

Gráfico 1. Relação das escolas formadas pelo SPE em Juazeiro, Bahia, no período de 2009 a 2011.

Fonte: GGM, 2011

O Instrumento ${ }^{12}$ questionou: as parcerias porventura desenvolvidas, a interação unidade escolar $\mathrm{X}$ unidade de saúde da família, o envolvimento da comunidade escolar, as atividades desenvolvidas, as dificuldades e as sugestões. O Quadro 2 demonstra os principais aspectos abordados pelos documentos avaliados no que se refere à metodologia utilizada pelo SPE, e o alcance de intersetorialidade, interface saúde-educação e efetividade social de suas ações.

\section{Resultados}

3.1 No primeiro grupo de documentos relacionados, o Guia ${ }^{5}$ direcionou-se ao fomento de processos de educação permanente de profissionais de saúde e educação, utilizando-se da interface saúde-educação baseada na intersetorialidade como instrumento de efetividade social das práticas, superando iniciativas pontuais e gerando projetos inovadores, permanentes e integrados. Já o Manual Diretrizes ${ }^{7}$ fundamentou-se na criação e instrumentalização dos Grupos de Trabalho, que assumiriam compromissos para a efetividade da proposta, destacando a importância da criação de espaços de participação social e do respeito à autonomia e responsabilidade compartilhada entre Federação, estados e municípios. Compreendeu as finalidades do projeto com vistas: à redução das vulnerabilidades às DST, HIV/Aids, gravidez não planejada e a evasão escolar a esta relacionada, o uso de psicoativos, o fomento ao protagonismo juvenil. O Caderno de Atenção Básica ${ }^{8}$ enunciou o PSE, programa que se propunha a alcançar a integração com ensino de competência, a instrumentalização técnica de professores e funcionários das escolas e dos profissionais da Estratégia de Saúde da Família, para apoiar e fortalecer as iniciativas, a identificação e a vigilância das práticas de risco, o monitoramento e a avaliação da efetividade de suas iniciativas, visando melhorar o compromisso das escolas com a promoção de saúde da comunidade escolar. 
Quadro 2. Metodologia do SPE sob a luz da intersetorialidade, interface saúde-educação e efetividade social.

\begin{tabular}{|c|c|c|c|}
\hline \multirow{2}{*}{ Documentos } & \multicolumn{3}{|c|}{ Metodologia } \\
\hline & Intersetorialidade & Interface Saúde-Educação & Efetividade social \\
\hline $\begin{array}{l}\text { Publicações e } \\
\text { documentos oficiais }\end{array}$ & $\begin{array}{l}\text { Oficinas de planejamento } \\
\text { conjunto, inclusão de } \\
\text { dispositivos sociais (GF) } \\
\text { GTM, GTE, GTF e suas } \\
\text { atribuições (MD) } \\
\text { CAB }\end{array}$ & $\begin{array}{l}\text { Formação para profissionais de } \\
\text { saúde e educação (GF) } \\
\text { Integração saúde-educação } \\
\text { (MD) } \\
\text { Articulação de políticas que } \\
\text { assegurem ações em saúde de } \\
\text { crianças, adolescentes e jovens } \\
\text { (CAB) }\end{array}$ & $\begin{array}{l}\text { Metodologia participativa e } \\
\text { emancipatória (GF) } \\
\text { Impacto das ações nos projetos } \\
\text { político-pedagógicos das escolas e } \\
\text { ações em saúde (MD) } \\
\text { Inclusão das temáticas de } \\
\text { educação em saúde nos projetos } \\
\text { político-pedagógicos (CAB) }\end{array}$ \\
\hline $\begin{array}{l}\text { Construtos } \\
\text { elaborados pelos } \\
\text { atores sociais }\end{array}$ & $\begin{array}{l}\text { Oficinas temáticas (PrM) } \\
\text { Composição do GGM (Dec) }\end{array}$ & $\begin{array}{l}\text { Formação para profissionais de } \\
\text { saúde e educação (PrM) }\end{array}$ & \\
\hline $\begin{array}{l}\text { Relatórios de } \\
\text { avaliação }\end{array}$ & $\begin{array}{l}\text { Parcerias, envolvimento da } \\
\text { comunidade escolar (IM) }\end{array}$ & $\begin{array}{l}\text { Interação unidade escolar } x \\
\text { unidade de saúde da família } \\
\text { (IM) }\end{array}$ & \\
\hline
\end{tabular}

$\mathrm{GF}=$ Guia para a formação de profissionais de saúde e educação do SPE; MD = Manual Diretrizes para implementação do projeto SPE; $C A B=$ Caderno de Atenção Básica Saúde na Escola; PrM = Projeto municipal do SPE; Dec= Decreto Municipal 489/2009; IR= Informativo Relação das Escolas - SPE - 2009, 2010 e 2011; IM= Instrumento de Monitoramento

3.2 O segundo grupo discorreu, em relação ao Projeto ${ }^{9}$, que, dentre os resultados esperados, encontravam-se: o apoio técnico, percepção da postura dos profissionais com o tema sexualidade e relações de gênero, troca de experiências, reflexão sobre os arranjos familiares e a violência intra e extrafamiliar, sensibilização da comunidade escolar à adoção de condutas preventivas em DST/ HIV/Aids, e reflexão sobre métodos contraceptivos para o exercício da sexualidade com liberdade e responsabilidade. O Decreto Municipal ${ }^{10}$ antecipou a ampliação de parcerias visando: a integração de esforços para a formação integral do educando, fomento à participação juvenil, construção de uma rede integrada saúde-educação, contribuindo para a sustentabilidade das ações do SPE e consolidação das políticas públicas de proteção à adolescência e à juventude brasileiras.

3.3 O terceiro grupo de documentos apresentou, no Informativo ${ }^{11}$, que, em 2009, quatro escolas (40\% das escolas com profissionais formados pelas oficinas do projeto) implantaram o SPE, e o monitoramento ocorreu em sete escolas, o que representa $80 \%$ delas. Em 2010.1, apenas três escolas ( $27 \%$ das escolas) implantaram o SPE, ao passo que o monitoramento ocorreu em sete escolas. Em 2010.2, a implantação do SPE ocorreu em três escolas (15\% das unidades escolares), e o monitoramento das ações foi realizado em cinco unidades. Em 2011, nenhuma escola implantou o $\mathrm{SPE}$, e o monitoramento foi feito em uma escola (4\% do total das unidades escolares), o que pode ser visualizado no Gráfico 2.

O Instrumento ${ }^{12}$ espacializou que, das 53 escolas relacionadas, 21 implantaram o SPE, o que indica um percentual de 40\%. Dentre as parcerias citadas, encontravam-se: Programa Saúde da Família (PSF), Guarda Municipal, Universidade, Polícia Militar, Conselho Tutelar, Comunidade Escolar, Secretaria de Agricultura, Desenvolvimento Rural e Meio Ambiente (SEADRUMA), entre outras. O Setor Saúde e a interação unidade escolar $X$ unidade de saúde da família foram expressivamente citados, assim como o envolvimento da comunidade escolar: assistindo palestras e peça teatral, reuniões, organizando as ações, participando das oficinas, informes, videos, buscando parcerias, 
em visitas domiciliares, entrega de panfletos, dando suporte aos eventos. Quanto às atividades desenvolvidas, foram citadas: palestras com pais e alunos, divulgação e elaboração do projeto, danças, teatros, cordéis, jogos e brincadeiras em sala, confecção de cartazes, seminários, paródias, produções de texto, projeção de filmes, ação cidadania, produção de CD e DVD.

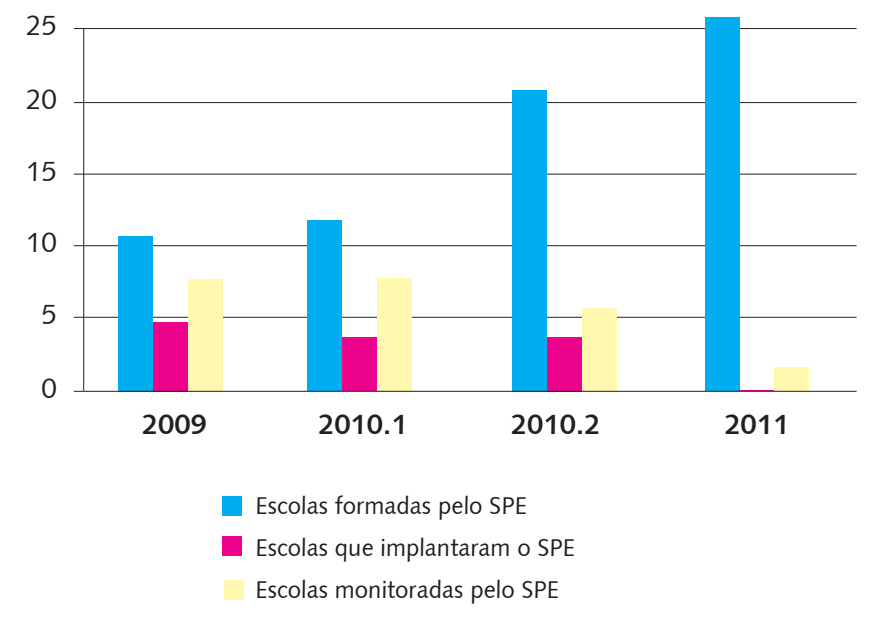

Gráfico 2. Situação de implantação e monitoramento do SPE.

Fonte: GGM, 2011.

Dentre as dificuldades, foram citadas: restrições no acesso à saúde, centralização da formação na figura de um profissional, e a consequente não-socialização do conhecimento, ausência de profissional especialista para ministrar palestra, despreparo de professores para manejar a temática, espaço físico, distanciamento, falta de interesse e compromisso dos participantes, dificuldade de firmar parcerias relacionada ao tempo disponível dos profissionais, e o agendamento sucessivo de palestras não realizadas. Como sugestões, o documento elencou o envio de palestrantes para: a implantação, união dos núcleos próximos, solicitação de apoio do PSF para realização de palestras, divulgação da implantação do projeto dentro da escola, inclusão de visitas de profissionais da Unidade de Saúde da Família no cronograma de horário de trabalho destes profissionais, formação de parcerias com os postos de saúde. O Quadro 3 espacializou os principais resultados encontrados na avaliação dos documentos mencionados acima na perspectiva da intersetorialidade, interface saúde-educação e efetividade social.

\section{Discussão}

Quanto às concepções, os documentos do primeiro grupo convergiam para a integração saúdeeducação. O Manual Diretrizes ${ }^{7}$ para a implementação do projeto SPE aponta para a intersetorialidade construída a partir da articulação solidária e participativa, o que convergiu com o Caderno de Atenção Básica Saúde na Escola, que retomou, também, a ferramenta do território para o alcance da efetividade social entre as ações propostas. Este conteúdo também foi apontado por todos os documentos analisados do primeiro grupo. 
Quadro 3. Resultados do SPE sob a luz da intersetorialidade, interface saúde-educação e efetividade social.

\begin{tabular}{|c|c|c|c|}
\hline \multirow{2}{*}{ Documentos } & \multicolumn{3}{|c|}{ Resultados } \\
\hline & Intersetorialidade & Interface Saúde-Educação & Efetividade social \\
\hline $\begin{array}{l}\text { Publicações e } \\
\text { documentos } \\
\text { oficiais }\end{array}$ & \multicolumn{3}{|c|}{$\begin{array}{l}\text { O GF utiliza a interface saúde-educação baseada na intersetorialidade como instrumento de efetividade } \\
\text { social de práticas } \\
\text { O MD fundamenta-se na criação de grupos de trabalho que assumem compromissos com a efetividade da } \\
\text { proposta } \\
\text { O CAB enuncia o PSE como integração escola-ESF visando melhorar o compromisso das escolas com a } \\
\text { saúde da comunidade escolar }\end{array}$} \\
\hline $\begin{array}{l}\text { Construtos } \\
\text { elaborados } \\
\text { pelos atores } \\
\text { sociais }\end{array}$ & & $\begin{array}{l}\text { Rede integrada saúde-educação para } \\
\text { redução dos agravos à saúde da } \\
\text { população jovem (Dec) }\end{array}$ & $\begin{array}{l}\text { Exercício da sexualidade com } \\
\text { liberdade e responsabilidade (PrM) } \\
\text { Fomento à participação juvenil para } \\
\text { transformação da realidade (Dec) }\end{array}$ \\
\hline $\begin{array}{l}\text { Relatórios de } \\
\text { avaliação }\end{array}$ & $\begin{array}{l}\text { Parcerias PSF, NECOM, } \\
\text { Guarda Municipal, UNIVASF, } \\
\text { PM, Conselho Tutelar, ACS, } \\
\text { Comunidade Escolar, CAPS, } \\
\text { Secretaria de Agricultura, } \\
\text { SEADRUMA, SIAN, } \\
\text { Agrovale, Secretaria de } \\
\text { Desenvolvimento (IM) }\end{array}$ & $\begin{array}{l}\text { A parceria com o setor saúde foi citada } \\
\text { no IM. A interação unidade escolar } x \\
\text { unidade de saúde da família. } \\
\text { A restrição do acesso à saúde, } \\
\text { ausência de profissional especialista. } \\
\text { Sugestão de apoio técnico do PSF, } \\
\text { inclusão de visitas do PSF, formação de } \\
\text { parcerias com os postos de saúde (IM) }\end{array}$ & $\begin{array}{l}\text { Implantação do SPE (IR) } \\
\text { Compromisso dos partícipes, } \\
\text { interesse, tempo disponível } \\
\text { dos profissionais, interesse da } \\
\text { comunidade sobre a questão } \\
\text { ambiental, centralização da } \\
\text { formação na figura de um } \\
\text { profissional, e a não-socialização do } \\
\text { conhecimento (IM) }\end{array}$ \\
\hline
\end{tabular}

$G F=$ Guia para a formação de profissionais de saúde e educação do SPE; $M D=$ Manual Diretrizes para implementação do projeto SPE; $\mathrm{CAB}=$ Caderno de Atenção Básica Saúde na Escola; PrM= Projeto municipal do SPE; Dec= Decreto Municipal 489/2009; IR= Informativo Relação das Escolas - SPE - 2009, 2010 e 2011; IM= Instrumento de Monitoramento

O território, para Fonseca ${ }^{4}$, é espaço e lugar construído socialmente, de conteúdo social, político e ambiental sobre o qual é possível atuar, eleito como estratégia para a coleta e organização de dados sobre ambiente e saúde, considerando os processos sociais e ambientais que transcendem esses limites. Sua peculiaridade mais importante é ser uma área de atuação, de fazer, de responsabilidade. O território é espaço comum para o qual convergem todos os setores sociais, sendo, portanto, elemento precioso para a compreensão das condições de vida e da dinâmica social. Esta fundamentação parece sustentar o seu uso pelos documentos analisados, sobretudo para a construção de planos de ação para a efetividade das práticas sugeridas.

A compreensão de território precede a compreensão de intersetorialidade, relacionada à interação e articulação entre todas as coisas, fazendo daquele um lugar saudável. A intersetorialidade é um processo de construção partilhada no qual diversos setores conjugam saberes e modos de fazer nucleares, porém abertos ao diálogo e à corresponsabilidade e cogestão para a melhoria do aparelhamento público. Segundo Barros e Castro ${ }^{14}$, deve responder às necessidades em saúde da população, sendo precedida de processos de levantamento diagnóstico, planejamento e avaliação participativa.

A efetividade social, entre os documentos do segundo grupo, foi apontada apenas pelo Decreto municipal ${ }^{7}$. Este conceito, segundo Belloni ${ }^{15}$, refere-se a critério de avaliação em políticas públicas que procura dimensionar os resultados da política pública, tanto econômicos quanto sociais. Estes resultados têm de ser compatíveis com as necessidades sociais e técnicas do mundo do trabalho.

Já a interface saúde-educação foi também prevista pelo Projeto municipal ${ }^{9}$, de modo similar ao Decreto ${ }^{10}$, que se direciona para a formulação de políticas integradas a partir de elementos de intersetorialidade.

A intersetorialidade foi parcialmente prevista, entre os documentos do terceiro grupo, por serem estes propostas relacionadas diretamente ao setor educação. Enquanto o Informativo ${ }^{11}$ apontou para 
um panorama geral do SPE na educação no município, o Instrumento apresentou possiveis articulações com outros setores da sociedade. A efetividade social, em ambos os documentos, foi condicionada pela implantação do SPE a partir da formação de profissionais. A interface saúde-educação foi timidamente visualizada no Instrumento pela relação da interação das unidades escolares e unidades de saúde da família e envolvimento da comunidade escolar, atividades desenvolvidas, dificuldades e sugestões apontadas pelo documento.

No primeiro grupo de documentos, a intersetorialidade foi contemplada por todos os documentos analisados, bem como a interface saúde-educação. A efetividade social também foi apontada por todos os documentos, orientados para a inclusão das políticas pelos projetos político-pedagógicos das escolas e na programação em saúde.

A efetividade social esteve presente, também, no segundo grupo de documentos, objetivada mais claramente pelo Decreto ${ }^{10}$. A interface saúde e educação foi prevista por ambos os documentos, e a intersetorialidade é assegurada pela organização do GGM, planejamento e implementação do projeto.

Ainda relacionado à intersetorialidade, o terceiro grupo de documentos lançou um olhar sobre o setor educação no município de Juazeiro, limitando a visualização deste elemento em seus conteúdos. A interface saúde e educação também foi timidamente apresentada pelo Instrumento ${ }^{12}$, enquanto a efetividade social, também limitada nesse estudo, foi apresentada pelos dois documentos.

No primeiro grupo de documentos, assim como no segundo grupo, a intersetorialidade, a interface saúde e educação, e a efetividade social foram previstas em todos os documentos analisados.

No terceiro grupo de documentos, o Informativo apresentou a efetividade a partir da formação e consequente implantação do SPE pelas unidades escolares, nos anos 2009, 2010 e 2011, sendo este indicador demonstrado a partir de baixos percentuais entre a quantidade de escolas formadas pelo SPE e a quantidade de escolas que o implantaram. O monitoramento desenvolvido nas escolas formadas também é indicador de efetividade do projeto. O mesmo, segundo o documento em questão, também apresentou números pouco significativos. Para o Instrumento ${ }^{12}$, a efetividade social, traduzida parcialmente nos $40 \%$ de implantação do SPE pelas escolas formadas pelo processo SPE, demonstrou pouca adesão ao projeto. Quanto à intersetorialidade, a presença de outros segmentos da sociedade civil nos processos de planejamento e execução de atividades demonstrou que este elemento esteve presente nos espaços disparados pelo SPE. A articulação com o Setor Saúde e a interação unidade escolar $X$ unidade de saúde da família surgiu de modo significativo na relação nominal, demonstrando que os atores que protagonizam o SPE talvez desconheçam que já faz parte do seu processo de organização e implementação, além de previsto e pré-requisito que o Setor Saúde o operacionalize de modo solidário com o Setor Educação. A participação da comunidade escolar foi citada de modo incipiente, sendo importante salientar, dentre as dificuldades citadas, a necessidade de disponibilização de profissionais de referência para a realização de palestras. O projeto SPE pressupunha a sustentabilidade de sua proposta, o que talvez não tenha sido esclarecido aos atores. Desse modo, são os próprios sujeitos e dispositivos sociais que integraram o SPE que o desenvolviam, inclusive metodologicamente.

\section{Conclusão}

A conclusão do presente estudo coincidiu com a aposta de inserir o Projeto Saúde e Prevenção nas Escolas (SPE) como políticas e práticas potentes, fortalecendo ações e orientando processos de educação permanente que conjugam atores e suas itinerâncias.

A experência SPE em Juazeiro apontou para o desenrolar de uma ação coplanejada por dois segmentos sociais, o setor saúde e educação. Sua construção e implementação apoiou-se nesta configuração, sendo, portanto, uma aposta intersetorial que, em sua concepção e metodologia, apresentou-se coerente com a proposta inicial, interministerial. Em seus resultados, o SPE emergiu por intervenções e reorientações que ressignificassem a essência do projeto e a colocassem em pauta junto aos protagonistas que o operam. 
A avaliação do SPE enquanto um projeto social contemplou admitir que a interface saúde e educação é possível considerando quais transformações sociais ela pode realizar, quem as realiza e por quê. Nesse sentido é que a avaliação permite elencar as melhores estratégias para que se alcancem os objetivos aos quais uma política está relacionada. Em Juazeiro, a integração saúde e educação foi possível e as transformações alcançadas, justamente porque houve efetivação da educação permanente e a implantação do SPE pelas escolas formadas.

Este estudo demandou a construção de espaços destinados à educação permanente, garantindo o encontro e a multiplicação das iniciativas pelos sujeitos implicados com o SPE, além de assegurar sua sustentabilidade reafirmando as ações encabeçadas por seus protagonistas. A pesquisa considerou oportuno fomentar a participação da comunidade escolar, sobretudo o protagonismo juvenil, e partilhar da responsabilidade sanitária com os demais segmentos sociais que compõem cada território.

Este trabalho, ao relatar a experiência do SPE em Juazeiro, reconheceu a limitação do seu estudo por se optar pela pesquisa documental, sendo de especial valia uma varredura mais detalhada sobre estes discursos, por quem fez o SPE acontecer. Por este motivo, este estudo não se esgotou por aqui, e carece de informações que o complementem.

É importante ressaltar o incansável trabalho do Grupo Gestor Municipal de Juazeiro que, aprendendo com os próprios passos, soube mediar e conduzir o projeto SPE, com persistência, coragem e enfrentamento.

Saúde e educação, hoje, dialogam como instrumentos de cidadania, que se relacionam entre si, conjugando a fluidez de uma rede, as práticas integrais e integradas, reorientações para o empoderamento e a transformação social. As iniciativas em saúde precisam contemplar, ainda, o setor educação, e vice-versa. Esta é uma relação indissociável para a garantia dos direitos fundamentais, tão inclusos nas agendas políticas atuais, e que para, se tornar realidade, demandam esforços coletivos.

\section{Colaboradores}

Os autores trabalharam juntos em todas as etapas de produção do manuscrito.

\section{Referências}

1. Constituição (1988). Constituição da República Federativa do Brasil: Brasília (DF): Senado Federal; 1988.

2. Faria RM, Bortolozzi A. Espaço, território e saúde: contribuições de Milton Santos para o tema da Geografia na Saúde no Brasil. RA'E GA. 2009; (17):31-41.

3. Freire P. Pedagogia da autonomia: saberes necessários à prática educativa. São Paulo: Paz e Terra; 2000.

4. Fonseca AF. O território e o processo saúde-doença. Rio de Janeiro: EPSJV/Fiocruz; 2007.

5. Ministério da Saúde. Secretaria de Vigilância em Saúde. Diretrizes para a implantação do Projeto Saúde e Prevenção nas Escolas. Brasília (DF): SEF; 2008. 
6. Laville CA, Dionne J. Construção do saber: manual de metodologia da pesquisa em ciências humanas. Porto Alegre: Artmed; 1999.

7. Ministério da Saúde. Secretaria de Vigilância em Saúde. Saúde e prevenção nas escolas: guia para a formação de profissionais de saúde e educação. Brasília (DF): SEF; 2008.

8. Ministério da Saúde. Secretaria de Atenção à Saúde. Departamento de Atenção Básica. Saúde na Escola. Brasília (DF): SEF; 2009.

9. Grupo Gestor Municipal (2008). Projeto municipal do Projeto Saúde e Prevenção nas Escolas. Juazeiro; 2009.

10. Prefeitura Municipal de Juazeiro. Decreto n 489/2009, de15 de outubro de 2009. Dispõe sobre a criação do Grupo Gestor Municipal para a implantação e implementação do SPE. Juazeiro: Gabinete do Prefeito Municipal; 2009.

11. Grupo Gestor Municipal (2008). Relação das Escolas - SPE - 2009, 2010 e 2011. Juazeiro; 2011.

12. Grupo Gestor Municipal. Instrumento de Monitoramento. Selo UNICEF. Tema: Saúde e prevenção nas escolas, na família e na comunidade. Etapa: Monitoramento. Juazeiro: UNICEF; 2011.

13. Gil AC. Como elaborar projetos de pesquisa. 4a ed. São Paulo: Atlas; 2002.

14. Campos GW, Barros RB, Castro AM. Avaliação de política nacional de promoção da saúde. Cienc Saude Colet. 2004; 9(3):745-9.

15. Belloni I. Metodologia de avaliação em políticas públicas: uma experiência em educação profissional. 4a ed. São Paulo: Cortez; 2007.

Ribeiro MSS, Ribeiro CV. Salud y Prevención en las Escuelas (SPE): elementos para evaluación de proyectos sociales en Juazeiro, Bahia, Brasil. Interface (Botucatu). 2015; 19(53):337-48.

El SPE presentado por la autora como TCC de Residencia Multi-profesional en Salud de la Familia, que en aquella época era alumna del programa, representó una iniciativa de salud y educación, promoviendo una actividad de salud sexual y reproductiva para los adolescentes en el municipio de Juazeiro/Estado de Bahia, Brasil. El objetivo fue analizar el SPE en su concepción, metodología y resultados, considerando la intersectorialidad, la interfaz entre salud y educación y la efectividad social. Este trabajo concluyó que era oportuna la garantía de sostenibilidad del proyecto y del fomento para la participación de la comunidad escolar. Los desdoblamientos del SPE se visualizan en las macro-políticas de atención a la salud y educación que hoy dirigen los principales pactos intersectoriales de este escenario, exigiendo la comprensión de su construcción para su fortalecimiento.

Palabras clave: Salud. Educación. Intersectorialidad. Efectividad social.

Recebido em 09/07/14. Aprovado em 27/08/14 